\title{
Fragmentos de historia popular. La subjetividad en la historia oral
}

\author{
Benjamín Garcia
}

\begin{abstract}
"Bueno, aquí me tocó. Es como cuando una corriente va y se queda una basura en, en alguin lugar, [risa]; así, unos nos quedamos aquí, otros allá, otros más allá, y así."
\end{abstract}

no de los factores a tomar en cuenta en todo estudio histórico es el de la subjetividad del conocimiento de los hechos sociales. En la historia oral por su misma naturaleza, ese factor viene a ser esencial, pues la voz de quienes dan testimonio de sus vivencias está impregnada de subjetividad, "el único y preciado elemento por el cual las fuentes orales se imponen sobre el historiador y que otras fuentes no poseen en la misma medida". ${ }^{2}$ Es decir, se considera que el mérito de la historia oral radica precisamente en aceptarla en su subjetividad, ${ }^{3}$ "subjetividad de historiado e historiador, [que] sin caer en el extremo idealista de que como todo conocimiento es subjetivo no se puede lograr realmente nunca un conocimiento de la realidad social", 4 no sacrifica los sentimientos personales puesto que son precisamente ellos los que conducen al conocimiento de las actitudes que rigen los hechos.

Por otra parte, entre los objetivos y soluciones que se propone la historia popular para el rescate de vivencias humanas a través de la historia oral, se encuentra "convertirse en escaparate de diversas experiencias; impresiones y opiniones acerca de pasajes relevantes de nuestra historia, pero también, y principalmente, de pequeños fenómenos que de alguna manera contribuyen a integrar nuestra historia", en "las voces de los actores, de los que lo vivieron; aquellos que -sin figurar siquiera en modestos periódicos locales- tuvieron alguna participación y desean opinar sobre lo que vieron y vivieron, aunque fuera en un segundo plano". ${ }^{6}$ Así, al hacer oír esas voces de los "sin historia", surgen los elementos que conforman el fuerte entorno subjetivo que los rodea, como lo podemos apreciar en el epígrafe, cuando el viejo villista, inquirido sobre el porqué de quedarse a vivir en Parral, contesta con voz llena

1 Entrevista a José Raya Rivera, realizada por Maria Isabel Souza el 20 de julio de 1973 en Parral, Chih., Archivo de la Palabra del Instituto de Investigaciones Dr. José Ma. Luis Mora, México, PHO/1/69, p. 27-28.

' José Lpis Huiza, "La investigación Linea Obrera 1900-1930", en Hacia la sistematización de la historia oral, Fundación Friedrich Ebert, Lima, Perú, 1985, p. 5.

"Wilma Derpich. "Aproximaciones metodológicas a la historia testimonial", en Hacia la sistematización.... op. cit.., p. 14.

+ Eugenia Meyer, "Consideraciones metodológicas y problemática de la historia oral en el campo de las ciencias sociales", texto inédito del IV Seminario de Metodologia de Historia Oral, INAH, 1981, p. 20.

"Eva Salgado A.. "Fragmentos de historia popular", en Secuericia núm. 2, México, mayo-agosto de 1985 , p. 185.

"Ibidem, p. 184. 
de fatalidad: "Aquí me tocó, como se queda una basura en cualquier lugar". La comparación de su existencia a una basura que la corriente de la Revolución dejó en cualquier sitio, es una expresión impregnada de lo más íntimo de sus sentimientos, expresión que proviene de su individualidad, de la apreciación que él tiene de sí mismo, de su lucha, de su vida dentro de un proceso histórico.

En esas consideraciones, y con el objetivo de hacer una aportación a la historia popular, así como de reflexionar, o hacer reflexionar, sobre el papel de la subjetividad en el conocimiento histórico, presentamos a continuación una serie de fragmentos tomados de entrevistas con participantes en la Revolución mexicana, que obran en poder del Archivo de la Palabra de nuestro Instituto. En dichos fragmentos encontraremos testimonios que nos adentrarán en los modos de pensar o de sentir de diversos informantes sobre hechos o experiencias en los que intervinieron, haciéndonos revivir con pelos y señales lo que los relatos históricos nos cuentan escuetamente como hechos.

El primer testimonio es sobre las batallas de abril de 1915 en Celaya; el informante, que militaba en las filas carrancistas, recuerda:

En el Guaje nos dieron una carga de caballeria que si sentiamos, bueno, un poquito de escozor en la espalda, porque fueron dos cargas fenomenales. Ya se nos figuraba que... llegaban a lazar las ametralladoras; a cabeza de silla se llevaron tres ametralladoras de nosotros. - ¿De qué manera se hacían estas cargas de caballería?

-Todas de golpe, como tratar de envolver... Vamos a suponer que esto es la línea de fuego, aquí de este lado están combatiendo, viene una carga de caballeria desde allá más o menos del frente que ocupa aquella línea de fuego, a cargar precisamente sobre de ellos. Naturalmente que... uno va a pie, ve el caballo, tiene que hacerse a un lado, si no lo matan, claro. Pero para desgracia, nos tocó la buena suerte que era tan vivo el fuego de las infanterias, que no necesitamos de eso...?

El segundo informante nos rememora un episodio de la lucha contra los huertistas en 1913 , cuando, a la edad de 18 años y por el descontento tras el asesinato de Madero, se lanzó a la lucha revolucionaria en la zona de Catemaco, Veracruz.

Nos pusimos en una emboscada. Cómo seriamos nosotros de hábiles para la guerra que, estando así el cerro, iba el camino serpenteando, y en vez de colocarnos en la parte de arriba, nos colocamos en la parte de abajo. ¿Qué le parece? [risa]. Bueno, pues ahí fue una cosa curiosa, porque estábamos ya en la emboscada bien colocados, listos, cerquita; el camino iba tan lejos como de la pared aquella. Estaba cerrado, tan cerrado el breñal, que lo veían a uno; estaba yo listo, con mi rifle 32-20. Pues al rato llegó otro correo y dicen: "Pues ya no, ya no..." Se regresaron y pues ya salimos al camino... [después]: ¡Pum, pum, pum!, los federales sobre nosotros, balaceándonos en el camino. Pues corriamos a nuestro puesto. Yo me quedé ahí cerca, cuando al rato va pasando pa donde estaba yo, [risa] ¡Válgame Dios! Yo volteaba a ver a los compañeros, no vi a nadie... Habian salido corriendo también. No

${ }^{7}$ Entrevista a Alfredo Rodriguez Arciga, realizada por Jaime Alexis Arroyo en marzo de 1961 en México, D. F., Archivo de la Palabra del Instituto Dr. José Ma. Luis Mora, México, PHO/1/102, p. 17. 
crea que me quedé por valiente. [Risa] $\mathrm{Y}$ es que yo estaba novato, señorita, no como esos rancheros que conocen los campos. Pues todo el afán mío fue quitarle la carabina, que la traía agarrada con una banderola, y así, en las ansias de la muerte, quitarle las cananas que traia, y salí corriendo. Pero como sali corriendo, el camino daba vuelta, y yo corrí en una dirección que oía voces y voces, y me acerco al camino: " ¡Compañeros, espérenme, que estoy perdido; compañeros, espérenme!” ¡Uh!, me han puesto una balacera... Eran federales. ¡Dios mio! Y ai voy corriendo otra vez por el otro lado. Sin comer más ese día -agua sí, porque allá hay por todas partes-. Pues llegué a un lugar que habia palma real y empecé a coger coyoles que hay abajo, que es la fruta que dan; se les quita la cáscara y a partirlos y a comer el huesito, a comer el huesito, tenía yo mucha hambre. Llevaba mi bolsa también de lona, y a llenarla, por si acaso no habiáa comida más adelante. Esa noche me tocó dormir arriba de un árbol, porque hay mucho tigre ahí. Arriba de un árbol y con mi carabina lista. Y el enemigo durmió muy cerca de donde yo estaba, también en un llanito. Y al día siguiente, señorita, dije: “¡Bendito sea Dios! ¡Yo estoy perdido!” Y me acordé de la Virgen del Carmen, de Catemaco: “ $\mathrm{AAy}$, Virgen del Carmen, sácame una vereda, que vea un camino que yo conozca, y te ofrezco una vela de a peso!" [Risa] Fijese usted, muchacho... estaba yo jovencillo. Pues no le miento, pero di una vuelta y ahí estaba una vereda de ganado, y esa vereda me sacó al camino [...] Y, corriendo, cuando iba corriendo, me encontré otra arma, una 30 tirada en el campo. Y resultó que era de uno de los compañeros que la había tirado. iFijese usted nomás lo que es el miedo! Y yo llegué con tres armas al campamento y creyeron que yo era una fiera, muy valiente. ${ }^{8}$.

En el siguiente testimonio, el entrevistado narra un hecho ocurrido durante la toma de Torreón en 1913 por las fuerzas villistas, en las que él militaba.

Un caso también curioso, de Torreón, que estando nosotros -porque los cuarteles los haciamos nosotros en carros, cajas, carros de ferrocarril, ahí veniamos todas las tropas- y fue una señora llorando a decir que el marido de su hija andaba golpeando a su hija, y que era un capitán que estaba ahí escondido. Y fueron unos soldados de ahí a sacarlo. Pues éste salió corriendo y fueron y lo alcanzaron y lo llevaron. Bueno, si había golpeado tanto a la mujer que estaba casi muerta. Entonces dieron la orden: "iCuélguenlo!" Eso es cosa verídica. Ya en eso nos dimos cuenta, los oficiales ayudaron a colgarlo, ya en eso nos dimos cuenta que era delahuertista, que se escondia, y fue a dar allá con la señora y la golpeó, y la suegra fue a dar el pitazo. Se lo llevaron y dieron orden de que lo colgaran, se iba a colgar. Que le decia a un soldado que estaba presente, se llamaba Pablo, al tiempo que echaba la cuerda al brazo del árbol... El pobre lloraba, el fulano ése, y decía: "No me cuelguen; fusilenme, mátenme de otro modo, pero no me cuelguen" - “Andale, si tú no mandas!" Cuando lo quisieron colgar, éste gritaba: "¡Virgen Santisima! „Virgen de San Juan! ¡Virgen de Guadalupe!" Pues, a los gritos, se rompe el brazo del árbol, se cae. "Pues no, tú no te escapas." Y volvió a echarla otra vez, a más alto, más fuerte, el sargento Pablo. Y entonces otra vez empezó a gritar y reviéntase la reata. Empezó a pedirle a los santos que no lo colgaran, que mejor lo tronaran. Se reventó la reata, y ya entonces estaban anudándola, y

${ }^{8}$ Entrevista a Constantino Caldero Vázquez, realizadá por Maria Isabel Souza el 27 de octubre de 1973 en Chihuahua, Chih., PHO/1/110, p. 13-16. 
corre el amigo ése; ya entonces se le cumplió su gusto: en la carrera se lo tronaron. Hay cosas que son verídicas.

Presentamos ahora una vivencia de un soldado villista surgida durante la toma de Zacatecas, en junio de 1914.

Cuando el sitio de Zacatecas, que duró como quince días o más, no recuerdo bien cuántos, pos nos daban descanso a diferentes grupos $p a$ que nos retiráramos del, del centro de..., de la línea de fuego, ¿verdá? $\mathrm{Y}$, y una noche que nos tocó..., que nos dieron descanso a, como a cinco, seis oficiales, compañeros míos, fuimos a una chocita ahí de unos campesinos, a buscar algo que comer. $Y$ era una señora mayor la que estaba ahi, porque a las muchachas las escondian porque, porque creían que los villistas éramos muy malos [risa], eso creían. Y era una viejita la que nos recibió ahí. Ya le dijimos que nos diera algo de comer y dijo: "Orita les hago". Mientras la viejita estaba haciendo la, la humilde merienda que nos iba a dar, nos quedamos dormidos todos los oficiales ahí; estábamos muy desvelados, hambreados y todo. Y nos despertó ella, le ha de haber dado lástima, ahí ver unos muchachos tan jovencitos y todo ahí un poco, un poco quizá decepcionados. Y el sitio todavia estaba en grande. Y entonces nos dijo la viejita: "Miren muchachos, ustedes están muy jóvenes. Yo les voy a decir una cosa: hay en Zacatecas, en el cerro... ¿de qué?, de la Bufa, hay un templo de la Virgen de... ¡Ah!, ¿qué Virgen, hombre, era?..., del Patrocinio. Ofrézcanle a la Virgen del Patrocinio que, que no los vayan a matar. Háganle una promesa o algo". Ella nos dijo eso a todos; ni caso le hicimos a la viejita, por... de boca, de palabra, para acá adentro lo guardamos todo. $P o s$ el día que ya, que ya entramos a Zacatecas era un laberinto aquello: los caballos revueltos con los hombres muertos, ahi reventándose, y los alambres de arriba abajo. Bueno, una cosa espantosa. Y como al tercer día [carraspea], me tocó a mí, me fui yo solo a subir el cerro de la Bufa. Y ai voy cayéndome, y pos al fin subí hasta arriba. Todavía había muertos adentro del templo y pos ahí me voy encontrando a todos los demás oficiales, pero ninguno fue junto con otro; todos fuimos y... nos dio vergüenza decir que ibamos a cumplir, pues, alguna promesa, ¿verdá? ${ }^{10}$

El mismo informante nos lleva hacia algunos recuerdos de la campaña de Sonora de la División del Norte, cuando ya este famoso ejército estaba en su última etapa de existencia, allá en los años finales de la primera década de este siglo.

[...] en la campaña esa de Sonora, atacamos Agua Prieta. Y allí, el herido que se, que se, balaceaba no había ni quien le untara ni siquiera saliva. Esos fueron cinco dias de sitio alli, y los mismos dias que no comió la tropa, porque no habia qué. Decian que nomás entrando a Agua Prieta nos hartaríamos; pero nunca entramos a Agua Prieta: nos corrieron [risa]. De ahi fuimos a un pueblito, Nacozari, cerca de Agua Prieta y, y alli fue la primera vez que nos repartieron harina; estaban los soldados, mmm, batiendo su masa, su harina, en los sudaderos de los caballos. fijese nomás; ahi, en una, en la orilla de un arroyo. Bueno, la guerra es asi, „verdâ?, tiene uno que, que asimilarse,

${ }^{9}$ Entrevista a Demetrio Camarillo, realizada por Jaime Alexis Arroyo en marzo de 196I en la ciudad de México. Archivo de la Palabra dél Instituto Dr. José Ma. Luis Mora, México, PHO/1/105, p. 12-13.

${ }^{10}$ Entrevista a Abel Pereira Moreno, realizada por Ma. Alba Pastor el 21 de julio de 1973 en Parral, Chih., Archivo de la Palabra del Instituto de Investigaciones Dr. José Ma. Luis Mora, México, PHO/1/74, 23-24. 
hacer a todas las consecuencias que traiga en sí, y no tiene remedio, sin llorar, [...] Y si llora uno, pues llora solo y quedito [risa], que no lo oigan.

También villista, el siguiente entrevistado recuerda con emoción su labor para luchar contra las tropas federales en los inicios de la Revolución Mexicana.

[...] Y luego luego de allí me fui y fui allá a mi rancho, y ahí tenía yo unas cajas de parque yo, y fui y metí una caja de parque a un puente que hay, regular de grande, que hay ahí, que había ahí, ya lo quitaron, y lo tumbé, hasta Chihuahua se oyó el estallido de la caja de pólvora. Y... y en la noche, ahí viene el tren de auxilio que le mandaban para levantar los de infantería que ayudan allá, a traerlos aquí y yo me fui allá a los cerros y tumbé el puente; búeno, no cayó el puente, tumbé la loza donde estaba el puente, para que quedara el puente volando, y... llegó el tren con carros, largos el tren, y yo lo estaba viendo ahí en la ladera del cerro, y luego un garrotero vino y revisó la vía y ya cuando se acercó al puente vio los rieles de un lado del puente al otro y creyó que estaba bien, y le dio señales al tren que avanzara, avanzó el tren y nomás la máquina entró al puente y uno o dos carros y... ipalo!, se fue pa'bajo. $^{12}$

Finalmente, para los siguientes informantes, ambos soldados en las filas villistas a las que se incorporaron a muy temprana edad, lo esencial es dejar establecida la realidad de lo que cuentan, su realidad $s u$ verdad.

- No, señorita, ya no. Ya le digo, yo, por mi parte, ya le digo, yo le digo lo que vide, yo no digo más. Y si usté me cree que a Villa lo mataron porque le tenian miedo, haga usted lo que guste... ¡Porque usté, usté es muy nueva, señorita! Usté no alcanzó a ver tanta cosa.

- Sí, claro, yo sé.

- ¿Mande?

- ¡No!, si le estamos preguntando es porque queremos, queremos rescatar lo que es verdad. $Y$ por eso le estamos preguntando.

- Pues yo le digo, yo le digo lo que vide, no, señorita. ${ }^{13}$

- Andábamos en Tierra Blanca, peliando, y resulta que le dieron un balazo a uno de los soldados y se le quedó en una costilla. Y aquél hombre, pos no podia andar y estaba una tormenta de balas. Pasaba un -ya no tenía yo con qué anestesiarlo, ya no tenía con qué vendar, ya se me habia acabado todo-, y pasaba un soldado con una botella de tequila; le dije: “¿Qué llevas ai?" - "Pos una botella de tequila". - "Traila porque lo necesitamos aquí". -"No, que ésta es mía". -"No, mira, aqui está enfermo, trai una bala; tráisela, que, que tome para que, pos, pa sacársela". Pos entonces ya se lo dio y se tomó casi media botella, ¿verdâ?, se emborrachó. Y entonces en un arroyito, allí, pues le saqué

1 Ibidem. p. 11.

12 Entrevista a Andrés Rivera Marrufo, realizada por Ma. Isabel Souza en General Trias, Chih., Archivo de la Palabra del Instituto de Investigaciones Dr. José Ma. Luis Mora, México, PHO/1/63, p. 38.

${ }^{13}$ Entrevista a Santos Márquez Parada, realizada por Ma. Alba Pastor el 16 de julio de 1973 en General Trias, Chih., Archivo de la Palabra del Instituto de Investigáciones Dr. José Ma. Luis Mora, México, PHO/1/64, p. 19 
la bala y le cosí pronto, ¿verdá? Y entonces siguió ya... peleando. Esa es como una especie de anécdota, ¿verdâ? Pero es cierto. [Risa]. ${ }^{14}$

¿Qué nos han revelado los testimonios anteriores? ¿Qué pensamientos, sentimientos, percepciones y actitudes se pueden intuir más allá de las palabras? Las respuestas provienen naturalmente de sus mismas palabras y traslucen emociones como el miedo, percepciones como la desgracia o la buena suerte, las actitudes de asombro ante hechos que por dramáticos parecerían no ser verídicos y que se resalta que sí lo son; la vergüenza de callar una promesa que externamente no se podía manifestar pero que si se iba a cumplir secretamente; el tener que aguantarse las ganas de llorar, o hacerlo sin que los oigan, factores todos de una subjetividad esencialmente presente en los testimonios hablados, y que son elementos que, a pesar de las criticas, hacen que "la historia oral sea insustituible para ingresar al mundo de las ideas, las percepciones, las emociones...", y práctica, que hará al informante integrarse a su. realidad y tener conciencia de ella. ${ }^{16}$

Además, asi se contribuye también a obtener uno de los propósitos establecidos por la historia oral: la humanización de la historia, ya que alcanzar ese objetivo es "sin duda, hacer una historia global, totalizadora; es indagar sobre los protagonistas desconocidos. [...] Entender y analizar, evaluar el comportamiento humano, interpretar el sentido político de los testimonios, vendría a ser el complemento de este proceso de historia oral que permite, en última instancia, estudios del hombre común en un planteamiento más absoluto"."

14 Entrevista a José Rava Rivera, op. cit., p. 19-20.

is Wilma Derpich, op. cit., p. 14.

${ }^{16}$ Eugenia Meyer, op. cit., p. 20.

i7 Ibidem, p. 16-17. 